\title{
ANÁLISIS DEL FEMICIDIO: TIPIFICACIÓN Y REALIDADES EN EL ECUADOR
}

\section{FEMICIDE ANALYSIS: TYPIFICATION AND REALITIES IN ECUADOR}

\author{
Abg. Andrea Gabriela Zuleta Sánchez, Mgtr. \\ Magíster en Derecho Constitucional (Ecuador). \\ Docente Tiempo Completo de la Facultad de Derecho y Gobernabilidad de la \\ Universidad Tecnológica ECOTEC, Ecuador \\ azuleta@ecotec.edu.ec
}

\section{ARTÍCULO DE REFLEXIÓN}

Recibido: 10 de septiembre de 2019.

Aceptado: 11 de octubre de 2019.

\section{RESUMEN}

En el presente artículo se analizó el tipo penal tipificado en el 2014 "Femicidio", desde una óptica académica, partiendo en primer lugar de la figura en América Latina ya sea Femicidio o feminicidio, sus sanciones en cada país y los motivos para la tipificación, en la legislación ecuatoriana contrastada con la realidad social. El diseño del presente trabajo, se realizó desde el estudio bibliográfico e investigativo deductivo, de tratadistas relevantes del que se pudo como se ha tipificado el delito de dar muerte a una mujer por razones de género y se evidenció que las sanciones pueden llegar desde los doce años hasta cadena perpetua dependiendo el dilucidar que, no obstante a la visibilización que se ha conseguido a través de la tipificación y campañas de concientización, las cifras de femicidios no parecen disminuir.

Palabras clave: Feminicidio, femicidio, derechos humanos, violencia de genero.

\section{ABSTRACT}

ISSN: 1390-9320, Edición Especial, diciembre 2019 
This article analyzed the criminal type typified in 2014 "Femicide", from an academic point of view, starting first of all in Latin America, whether Feminicide or Femicide its sanctions in each country and the reasons for the classification, in Ecuadorian legislation contrasted with social reality. The design of the present work, was carried out from the deductive bibliographic and investigative study, of relevant writers of which it was possible to have typified the crime of killing a woman for reasons of gender and it was evident that the sanctions can come from twelve years up to life imprisonment depending on the elucidation that despite the visibility that has been achieved through typing and awareness campaigns the femicide figures do not seem to decrease.

Keywords: Feminicide, femicide, human rights, gender violence.

\section{INTRODUCCIÓN}

La conceptualización, el contenido y alcance del femicidio ha generado amplios debates en el interior del tejido social, considerando que su dinámica teórica sigue transformándose no obstante las pioneras en abordar el término como constructo teórico son (Radford \& Rusell, 1992, p. 34), el mismo que aparece como resultado de un continuado ejercicio de activismo por parte de las feministas y activistas de derechos humanos, que buscaban visibilizar la existencia de la muerte por condiciones de género, que si bien la apropiación específica data de 1990, es ante el Primer Tribunal Internacional de Crímenes Contra Mujeres, celebrado en Bruselas que marca históricamente un avance contundente relacionado a establecer la existencia del problema.

Los resultados de la iniciativa gestada entre los años 80-90, permitió que se configuraran investigaciones para comprender el fenómeno que por la asimetría estructural e histórica, se consideraban dentro de un ámbito privado y meramente doméstico, es por ello, que (Lagarde, 2009, p. 126), define al feminicidio como el patrón de criminalidad e impunidad por la violación continua de los derechos 
humanos de las mujeres dentro de un sistema deficiente, con ausencia de legislación y políticas públicas de protección.

Siendo así que los términos femicidio/feminicidio, confluyen hacia un mismo objetivo tiene componentes particulares y autónomos, por ello, el femicidio se refiere a la muerte violenta de mujeres por el hecho de serlo; y, el feminicidio tiene connotación con la inercia estatal que por omisión o negligencia contribuye a la impunidad y la orfandad de leyes y políticas que protejan a las mujeres.

El Comité de Expertas y expertos, que forma parte del "Mecanismo de Seguimiento de Implementación de la Convención de Belém do Pará", denominado "MESECVI", adoptó la Declaración sobre el Femicidio (OEA, 2012, pág. 29) y definió al Femicidio como la muerte violenta de mujeres por razones de género; sin importar si este tiene lugar dentro de la familia, unidad doméstica o en cualquier otra relación interpersonal; en la comunidad, por parte de cualquier persona, o que sea perpetrada o tolerada por el Estado y sus agentes, por acción u omisión (ONU O. d., 2008). No obstante, estas muertes tienen un origen y una causa que contiene un marcado elemento socio cultural, por lo que es imperante analizar la naturaleza social del mimo con la finalidad de complementar el análisis.

La importancia del abordaje del Femicidio, radica en transversalizar la construcción social de género, potenciando el análisis de las desigualdades entre hombres y mujeres debido a los estereotipos, construcciones sociales y culturales desfiguradas que identifican lo masculino y lo femenino asignándoles características inequitativas y excluyentes entre sí, así como la propia historia común de nuestros pueblos que ubican a la violencia en contra de mujeres y niñas, como parte de un entramado, no solo natural sino que culturalmente aceptado por la sociedad latinoamericana. Es notorio desde esa perspectiva que el objeto de éste recorrido no sólo establece un abordaje al tipo penal sino a al tejido diverso que conforma la construcción de género. Afrontar temas como este, genera implicaciones trascendentales en la dinámica social, así esta legítima potestad estatal de imponer el derecho de penalizar es el dique de contención contra acciones que han sido invisibilizada por años. Lo que 
transforma a la problemática en un reto del cual generar una cultura con perspectiva de género es vital, donde se excluye del discurso la impunidad e indiferencia.

Este articulo tiene como objetivo general establecer la importancia de la tipificación de Femicidio en virtud del auge preocupante de violencia que se evidencia en el Ecuador.

La presente investigación tiene como objetivo principal establecer la importancia de la normativización del Femicidio en el Ecuador. Por esta razón, se evidencian a continuación las etapas a cumplir para su cumplimiento: Identificar el recorrido histórico que ha permitido la tipificación del Femicidio o feminicidio, determinar doctrinariamente los tipos de femicidio y establecer como esta normado Femicidio en el Código Orgánico Integral Penal COIP.

\section{MATERIALES Y MÉTODOS}

El enfoque de la presente investigación se caracteriza por un análisis de la Figura del Femicidio, en el Ecuador analizándola desde un punto de vista académico y libre posturas radicales, en tal sentido se implementaron los métodos, descriptivo y teórico jurídico, además de contar con los tipos de investigación cualitativa, con la finalidad de construir un apropiado entendimiento del presente proyecto de investigación.

El método cualitativo tiene como principal característica la comprensión de fenómenos y emociones y el entendimiento de ciertas situaciones, además de un estudio interpretativo de los fenómenos que enmarcan el proyecto de investigación.

El método descriptivo se encarga de la descripción de la información y particularidades de un sector específico de la población, además su finalidad es tener como base una información específica y exacta, muy rara vez se emplean factores experimentales en este método.

El miedo de ser asesinada por un hombre es probablemente, lo que la mayoría de las mujeres sienten más a lo largo de sus vidas (Campbell, 1992), Es Suficiente ver las noticias para evidenciar que la violencia en contra de las mujeres está en un 
lamentable auge en el américa Latina y el mundo, considerado un flagelo social, que requiere impostergables esfuerzos para su sanción y prevención. En el Ecuador, cada 3 días se reporta un nuevo caso de femicidio. Así lo señalan los registros de cuatro organizaciones de la sociedad civil: Fundación Aldea, Red de Casas de Acogida, Taller Comunicación Mujer y la Comisión Ecuménica de los Derechos Humanos.

Por lo que se requiere abordar con determinación y total compromiso una realidad que ha sido invisibilizada por años, la marcada desigualdad y el costo real de enfrentar un engranaje social, en el que la figura de la mujer ha sido reducida a la esfera de lo privado, producto de que la sociedad que ha separado y delimitado las esferas de lo femenino y masculino.

Producto de lo cual ha mantenido una lucha inclaudicable contra la desigualdad generada por las múltiples formas de discriminación, lo que como respuesta ha generado una conquistas para la consecución de la lgualdad, la misma que ve reflejado los frutos de esa lucha en el Siglo XXI, donde con mayor fuerza se exige un reconocimiento de derechos que minimice las brechas existentes y permita disminuir las amplias estadísticas que evidencian una violencia creciente hasta su extrema expresión como lo es el Femicidio.

La penalista española (Copello, 2012) sostiene: "La categoría del femicidio permite hacer patente que muchos casos de muerte no natural de mujeres no son hechos neutros en los que resulte indiferente el sexo del sujeto pasivo sino que les ocurre a las mujeres precisamente por ser mujeres, como consecuencia de la posición de discriminación estructural que la sociedad patriarcal atribuye a los roles femeninos. La concepción amplia del femicidio-que abarca todas las muertes evitables de mujeres derivadas de la discriminación por razón de género- permite distinguir dos grandes grupos dentro de esta categoría: (a) las muertes violentas constitutivas de delito y (b) otras muertes evitables de mujeres no criminalizadas". 


\section{REVISIÓN TEÓRICA}

\section{Tipos Doctrinarios de Femicidio}

Durante la elaboración de este artículo de la revisión de múltiples tratadistas se encontraron no solo pluralidad de conceptos o definiciones del Femicidio, sino que también categorías, por lo que ha sido imperante incluir un capítulo destinado únicamente a mostrar los tipos de femicidios que desde la doctrina se mencionan. La tratadista Costarricense Ana Carcedo ha realizado una categorización de los tipos que ella considera existen de Femicidios englobándolos en tres tipos femicidio íntimo, no íntimo y por conexión que se desarrollaran a continuación.

\section{- Femicidio íntimo:}

Son aquellos cometidos por hombres con quien la víctima tuvo o tenía o una relación íntima, familiar, de convivencia, o afines a estas. Carcedo \& Sagot (2000) crearon una tipología propia para diferenciar el femicidio de los crímenes de homicidios de mujeres y para definir los crímenes de femicidio, en femicidio íntimo, no íntimo y por conexión. En primer lugar, el homicidio de mujeres por parte de sus compañeros, ex compañeros y familiares, con quienes la víctima convive, constituye el "femicidio íntimo Femicidio íntimo es decir cometidos "por hombres con quienes la víctima tenía o tuvo una relación íntima, familiar, de convivencia, o afines a éstas".

\section{- Femicidio no íntimo:}

Son aquellos cometidos por hombres con quienes la víctima no tenía relaciones íntimas, familiares, de convivencia, o afines a estas. Frecuentemente, involucra el ataque sexual de la víctima. En esta categoría se encuentran los delitos cometidos por hombres con quienes la víctima no tenía relaciones íntimas, familiares, de convivencia, o afines a estas, pero con los cuales existía una relación de confianza, de jerarquía o amistad (Carcedo \& Sagot., 2000). 


\section{- Femicidio por conexión:}

Se hace referencia a las mujeres que fueron asesinadas "en la línea de fuego" de un hombre tratando de matar a otra mujer. Este es el caso de mujeres que trataron de intervenir o que simplemente fueron atrapadas en la acción del femicida. (Carcedo \& Sagot., 2000).

Pero no solo el Femicidio puede ser cometido por agentes masculinos (Russell, 2006) considera que existen tres tipos de Femicidio en el que la mujer es sujeto activo del delito y estos pueden ser, cuando la Mujer actúa como agente del patriarcado, la mujer actúa como agente de perpetradores masculinos, o actúa por sus propios motivos.

\section{- La mujer como Agente del patriarcado:}

En este caso se observan los infames asesinatos relacionados con la dote, o aquellos en los que se prefieren los hijos varones por lo que se comete infanticidio o se descuida a la niña para evitar que sobreviva, las muertes relacionadas a la ablación o mutilación genital producto de infecciones, o en el momento del alumbramiento producto de la mutilación, así como forzar a las mujeres y niñas a someterles a operaciones primitivas que generan la muerte de la fémina.

\section{- La mujer como Agente de perpetradores masculinos:}

En este grupo se encuentran aquella mujer cómplice de delitos contra mujeres que para evitar que escapen las víctimas o se denuncie a los agresores cometen o son cómplices de femicidio; Inducción al suicidio que realiza la mujer por la violencia ejercida por un hombre a otra mujer a quien psicológicamente induce la idea de acabar con su vida. 
- La mujer actúa por motivos propios:

Estos son los casos de asesinatos en los que la principal motivación es el celo, codicia, inducción al suicidio por acoso producido por otras mujeres, asesinatos por ira, por ideologías políticas o religiosas extremistas.

\section{Tipificación del Femicidio/ Feminicidio en América Latina.}

En virtud que desde el año 2007 cada uno de los países de América Latina comenzaron a tipificar ya sea usando la denominación femicidio o feminicidio; para adentrarnos en este tema e imperante recordar que existe un sinnúmero de fórmulas legales para delimitar el femicidio/ feminicidio y es precisamente el ejercicio de adecuación de cada legislación a su realidad más cercana lo que genera una dispersión conceptual, sin embargo, esto no debe restar importancia al esfuerzo internacional para el pleno reconocimiento social de los derechos olvidados durante años (Laurenzo, Maqueda, \& Rubio, 2012).

El presente cuadro pretende graficar, no solo cual fue la figura acogida, sino que realiza una comparación de las sanciones que son aplicables en cada país, lo que permite, tener una idea general de la situación latinoamericana.

\begin{tabular}{|c|c|c|c|c|}
\hline PAís & Tipificación & Codificación & Forma & Sanción en Años \\
\hline MEXICO & Feminicidio & 2007 & $\begin{array}{l}\text { Tipo Penal } \\
\text { Autónomo }\end{array}$ & 40-60 Prisión y multa \\
\hline GUATEMALA & Femicidio & 2008 & $\begin{array}{l}\text { Tipo Penal } \\
\text { Autónomo }\end{array}$ & $\begin{array}{l}\text { 25-50 Prisión sin } \\
\text { posibilidad de } \\
\text { reducción ni sustitutiva }\end{array}$ \\
\hline HONDURAS & Femicidio & 2013 & $\begin{array}{l}\text { Tipo Penal } \\
\text { Autónomo }\end{array}$ & 30-40 reclusión \\
\hline
\end{tabular}

ISSN: 1390-9320, Edición Especial, diciembre 2019 


\begin{tabular}{|c|c|c|c|c|}
\hline NICARAGUA & Femicidio & 2012 & $\begin{array}{l}\text { Tipo Penal } \\
\text { Autónomo }\end{array}$ & 15-30 Prisión \\
\hline COSTA RICA & Femicidio & 2007 & $\begin{array}{l}\text { Tipo Penal } \\
\text { Autónomo }\end{array}$ & 20-35 Prisión \\
\hline PANAMA & Femicidio & 2013 & $\begin{array}{l}\text { Tipo Penal } \\
\text { Autónomo }\end{array}$ & 25-30 Prisión \\
\hline COLOMBIA & Feminicidio & 2008 & Agravante & 33.3 -50 Presidio \\
\hline VENEZUELA & Homicidio & 2007 & Agravante & 28-30 Prisión \\
\hline ECUADOR & Femicidio & 2014 & $\begin{array}{l}\text { Tipo Penal } \\
\text { Autónomo }\end{array}$ & 22-26 Prisión \\
\hline PERU & Feminicidio & 2011 & $\begin{array}{c}\text { Reforma: } \\
\text { Delito de } \\
\text { parricidio en } \\
\text { el Código } \\
\text { Penal }\end{array}$ & $\begin{array}{c}15 \text { Presidio -Cadena } \\
\text { Perpetua }\end{array}$ \\
\hline BOLIVIA & Feminicidio & 2013 & $\begin{array}{l}\text { Tipo Penal } \\
\text { Autónomo }\end{array}$ & $\begin{array}{l}30 \text { Presidio sin } \\
\text { derecho a Indulto }\end{array}$ \\
\hline BRAZIL & Feminicidio & 2015 & $\begin{array}{l}\text { Tipo Penal } \\
\text { Autónomo }\end{array}$ & $\begin{array}{c}\text { 12-30, suma de penas } \\
\text { en pluralidad de } \\
\text { víctimas, agrava } \\
\text { (embarazada, recién } \\
\text { dada a luz, } \\
\text { discapacitada, menor } \\
\text { de } 14 \text { o mayor de } 60 \text { ) }\end{array}$ \\
\hline CHILE & Femicidio & 2012 & $\begin{array}{c}\text { Reforma: } \\
\text { Delito de } \\
\text { parricidio en } \\
\text { el Código } \\
\text { Penal }\end{array}$ & $\begin{array}{c}\text { Presidio Mayor (15-20) } \\
\text { o Presidio Perpetuo } \\
\text { (No se considera } \\
\text { libertad condicional } \\
\text { hasta } 40 \text { años de } \\
\text { cárcel cumplidos) }\end{array}$ \\
\hline
\end{tabular}

ISSN: 1390-9320, Edición Especial, diciembre 2019 


\begin{tabular}{|c|c|c|c|c|} 
ARGENTINA & Homicidio & 2012 & Agravante & $\begin{array}{c}\text { Prisión o Reclusión } \\
\text { Perpetua }\end{array}$ \\
\hline $\begin{array}{c}\text { EL } \\
\text { SALVADOR }\end{array}$ & Feminicidio & 2010 & $\begin{array}{c}\text { Tipo Penal } \\
\text { Autónomo }\end{array}$ & $20-35$ años \\
\hline
\end{tabular}

Cuadro 1. Legislación comparada en América Latina respecto a la tipificación del asesinato de mujeres.

Fuente: Elaboración propia.

Tal como se observa en el cuadro comparativo sea el termino Femicidio o Feminicidio, el que se tipificara en cada país, las sanciones pretenden ser disuasivas, ya que las mismas en regla general contienen penas altas, como respuesta estatal de frenar una latente realidad. Y que emergen de un compromiso internacional, donde los Estados han articulado acciones para la sanción de la violencia como sistema de dominación. En el caso de Honduras, Costa Rica, Nicaragua, Panamá, Guatemala y Ecuador adoptaron la Figura del Femicidio. Mientras que México, El Salvador, Perú y Bolivia lo denominan feminicidio. El feminicidio constituye una forma de barbarie, la otra barbarie en el patriarcado de la era de la globalización, tal como señala (Monárrez, 2009).

\section{Importancia de la Tipificación del Femicidio dentro del Ordenamiento Jurídico Ecuatoriano.}

Antes de analizar el tipo penal como tal, es imperante reconocer que la Constitución del 2008, representa en sí misma el reconocimiento y optimización de las luchas de los movimientos sociales, que históricamente han tenido una gran incidencia, no obstante, la Constitución gestada en Montecristi, configura el derecho a una igualdad formal, igualdad material y no discriminación.

En ese sentido (Williams, 2009), establece que desde una perspectiva histórica la igualdad ha sido entendida de tal forma que ha promovido y ha escondido la discriminación, es decir, la igualdad ha acentuado diferencias. 
Uno de los avances más significativos de la constitución de Montecristi fue no solo la incorporación y desarrollo el acceso a la justicia para las mujeres, la imprescriptibilidad de delitos relacionados con violencia de género e intrafamiliar, un sistema de justicia eficiente, ágil, libre de corrupción y que termine con la impunidad. La protección integral de las víctimas de violencia, la reparación y restitución de derechos.

Dentro de la CRE vigente desde el mes de octubre del 2008, se consagran con característica de preceptos constitucionales la igualdad, equidad y no discriminación con el fin de alcanzar una sociedad que brinde participación equitativa, igualdad de oportunidades y la erradicación de usos y prácticas discriminatorias dentro del estado.

Se constituye como deber primordial del Estado Ecuatoriano, garantizar "el efectivo goce" de los derechos establecidos tanto en la Constitución como en instrumentos internacionales de derechos, el ejercicio de los derechos se regirá por los principios de igualdad y no discriminación tal como lo establece la (Asamblea Nacional Constuyente, 2008) en su artículo 11 numeral 2.

En el capítulo sexto que contiene los Derechos de libertad en su artículo 66 se reconoce y garantizará a las personas un catálogo de derechos los mismos que se enunciaran brevemente; en el numeral 1 el derecho a la inviolabilidad de la vida; en el numeral 3 la integridad personal tanto la integridad física, psíquica, moral y sexual como una vida libre de violencia en el ámbito público y privado.

Lo que genera además en una obligación estatal del Estado de adoptar las medidas necesarias para prevenir, eliminar y sancionar toda forma de violencia, en especial la ejercida contra las mujeres, niñas, niños y adolescentes, personas adultas mayores, personas con discapacidad y contra toda persona en situación de desventaja o vulnerabilidad; idénticas medidas se tomarán contra la violencia, la esclavitud y la explotación sexual. Así como en el numeral cuarto del mismo artículo se garantiza el derecho a la igualdad formal, igualdad material y no discriminación (Asamblea Nacional Constuyente, 2008). 
Como lo plantean las autoras Diana Russell y Jill Radford al llamar a las muertes de mujeres por su condición de género femicidio, se remueve el velo oscurecedor con el que las cubren términos "neutrales" como homicidio o asesinato.

El concepto de femicidio es necesario porque indica el carácter social y generalizado de la violencia basada en la inequidad de género y nos separa de planteamientos naturalizados, individualizantes, o patologizados que tienden a culpar a las víctimas revictimizándolas, al graficar a los agresores como "locos", "fuera de control" o "animales" o a concebir estas muertes como el resultado de "problemas pasionales". Estos planteamientos, producto de mitos muy extendidos, ocultan y niegan la verdadera dimensión del problema, las experiencias de las mujeres y la responsabilidad de los hombres. Es decir, el concepto de femicidio ayuda a desarticular los argumentos de que la violencia de género es un asunto personal o privado y muestra su carácter profundamente social y político, resultado de las relaciones estructurales de poder, dominación y privilegio entre los hombres y las mujeres en la sociedad (Carcedo \& Sagot, 2000).

Desde otra óptica, tener esta denominación permite discriminar los femicidios de los asesinatos de mujeres, es decir, aquellos, en los que, según lo que sostiene Russell: "el género femenino de una víctima es irrelevante para el perpetrador. Por ejemplo, un varón armado que dispara y mata a los propietarios, hombre y mujer, de un supermercado en el transcurso de su crimen, no ha cometido un feminicidio (Russell, 2006).

De acuerdo a los organismos de protección de derecho humanos, el femicidio constituye una violación de los derechos humanos de las mujeres que lleva consigo el incumplimiento de las obligaciones internacionales contraídas por los Estados conforme la Convención de Belén do Pará.

\section{Femicidio en el Código Orgánico Integral Penal COIP}


La fenomenología que responde a la creación del tipo penal Femicidio como una manera de dar una respuesta común desmontando todo el aparataje ideológico que nos limita la comprensión y la posibilidad de una vida conjunta, es decir, el género debe ser un punto de partida como dijera (Godelier, 2004) la situación de las mujeres es claramente de subordinación, es decir, separadas del principal factor de producción (tierra) y de los principales medios de destrucción (armas), excluidas históricamente del conocimiento.

El Código Orgánico Integral Penal en sus artículos 141 tipifica el Femicidio indicando que será sancionada con pena privativa de libertad de veintidós a veintiséis años la persona que, como consecuencia de relaciones de poder mediante cualquier forma de violencia, provoque la muerte a una mujer por el hecho de ser mujer o por su condición de género (Asamblea Nacional, 2014).

Con la finalidad de analizar esta figura, se desglosa el artículo previamente enunciado:

Sujeto Activo: INDETERMINADO es imperante indicar que en este delito es indeterminado en virtud que el artículo 141 del COIP, utiliza la expresión: "la persona que" lo que conlleva que el sujeto activo del delito de femicidio puede ser un hombre o de una mujer es un sujeto sin definir y no calificado; no obstante, su acción debe ser el resultado de las relaciones de poder. La indeterminación genérica del sujeto activo rompe el esquema trazado por la doctrina feminista ya que partiendo desde el análisis de la Historia han sido los hombres quienes se han encontrado en posición de ventaja y superioridad frente a las mujeres, no obstante, no es una limitante respecto al sujeto Activo.

Sujeto Pasivo: DETERMINADO en el caso del Sujeto Pasivo del Femicidio debe ser una Mujer ya que en el artículo en mención este sujeto pasivo si está definido.

EI bien jurídico tutelado: Derecho a la Vida; El derecho a la integridad personal Los elementos normativos: "relaciones de poder manifestadas en cualquier tipo de violencia", "la condición de mujer", "la condición de género". Pero la condición de 
género como circunstancia motivante del femicidio, es una construcción cultural y social que va más allá de las diferencias sexuales.

En el Artículo 142 artículo se enlistan las circunstancias que agravan el delito en tal virtud se impone el máximo de la pena prevista es decir 26 años. En tal virtud las circunstancias agravantes del femicidio son:

1. Haber pretendido establecer o restablecer una relación de pareja o de intimidad con la víctima.

2. Exista o haya existido entre el sujeto activo y la víctima relaciones familiares, conyugales, convivencia, intimidad, noviazgo, amistad, compañerismo, laborales, escolares o cualquier otra que implique confianza, subordinación o superioridad.

3. Si el delito se comete en presencia de hijas, hijos o cualquier otro familiar de la víctima.

4. El cuerpo de la víctima sea expuesto o arrojado en un lugar público.

Este delito cuenta con circunstancias agravantes propias de este delito, por el contenido de las agravantes previstas en los numerales, uno, dos y tres, se puede inferir que el legislador considere que la gravedad de este delito se ve incrementada cuando se comete en procura de establecer o restablecer en una relación de pareja o íntima, exista o haya existido relaciones familiares, conyugales y otras, o cuando se comete en presencia de los hijos o un familiar.

No obstante, eso no significa que no puedan coincidir con las 19 circunstancias agravantes de la infracción penal que se encuentran tipificadas en el artículo 47; en tal virtud en el evento que luego del proceso se establezca la presencia de una o más agravantes el Tribunal que conozca la causa impondrá la pena máxima prevista en el tipo penal, 35 aumentada en un tercio, conforme lo dispone el artículo 44 del Código Orgánico Integral Penal. Es decir, ya que la pena máxima 26 años de privación de libertad, existiendo agravantes generales de la infracción penal, esta pena se incrementa en un tercio, esto es 8 años 6 meses, dando como resultado una pena privativa de libertad de 34 años 6 meses. 
Uno de los casos que mayor conmoción social ha causado es precisamente el de Diana Carolina una joven de 22 años que fue asesinada en la ciudad de Ibarra frente a testigos entre los que se encontraban varios miembros de la Policía Nacional quienes no pudieron hacer nada para evitar que su victimario le propinara varias puñaladas que le ocasionaron la muerte a la ecuatoriana que se encontraba en estado de gestación a manos de su pareja de un ciudadano extranjero.

Cada 72 horas en Ecuador una mujer es víctima de femicidio. Al 29 de mayo de este año, se registraron 39 mujeres víctimas de femicidio. En el 89\% de casos los femicidas fueron ex parejas, novios o esposos. El $26 \%$ de las víctimas mortales ya habían reportado incidentes violentos, pero no fueron protegidas. En consecuencia, 47 niños, niñas y adolescentes han quedan en la orfandad (CEPAM, 2019).

Por lo que se constata la necesidad de la tipificación desde el año 2007 cada uno de los países de América Latina comenzaron a tipificar ya sea usando la denominación femicidio o feminicidio; para adentrarnos en este tema es imperante recordar que existe un sinnúmero de fórmulas legales para delimitar el femicidio/ feminicidio y es precisamente, el ejercicio de adecuación de cada legislación a su realidad más cercana lo que genera una dispersión conceptual, sin embargo esto no debe restar importancia al esfuerzo internacional para el pleno reconocimiento social de los derechos olvidados durante años (Laurenzo, Maqueda, \& Rubio, 2012).

No obstante, el establecimiento de la conducta típica antijurídica del femicidio en nuestra legislación penal, la tipificación ha logrado disminuir la tasa de mortalidad de las mujeres por femicidio y de hecho la misma sigue en aumento, lo cual implica que la responsabilidad de esta situación recaiga sobre la sociedad que ha creado una estructura flagelaría que lacera los derechos femeninos.

Que la tipificación de la Figura del femicidio ha permitido visibilizar una realidad escondida en las estadísticas generales del homicidio o asesinato y ha permitido, que cuando se cumplen los presupuestos del artículo 141, del Código Orgánico Integral Penal; es decir, como resultado de relaciones de poder a través de cualquier tipo de 
violencia, de muerte a una mujer, por el hecho de ser mujer o por su condición de género imponiendo una pena privativa de la libertad de 22 a 26 años, y en el caso que se configuren los agravantes considerados en el artículo 142, se impondrá el máximo de la pena.

\section{CONCLUSIONES}

Al iniciar este artículo se planteó como objetivo general "Establecer la importancia de la normativización del Femicidio en el Ecuador". De la revisión de todos los trabajos bibliográficos, estudios y pensamientos que anteceden se ha concluido que la positivización del femicidio en el Ecuador no solo se debía a una obligación internacional, generada por la convención de Belén du Para, sino también fue una respuesta moral, ante los casos que se presentan diariamente en las ciudades, comunidades y pueblos.

Si bien es cierto el resultado de la muerte de una mujer, ya sea por el hecho de ser mujer, o por una cosificación que genera en el agresor una certeza de pertenencia que le motiva a pensar erróneamente que puede tomar incluso su vida si así lo desea; lo que no es patrimonio del Ecuador objeto principal del estudio, si no se ha podido concluir que es una constante que se observa en los noticieros de toda América Latina; que se ha podido analizar entorno a las múltiples coincidencias socioculturales, económicas y jurídicas.

Esta positivización ha perseguido obtener un situar en el discurso de la criminalística moderna y pretende visibilizar un escenario de violencia sistemática, invisibilizada, silenciada y mantenida oculta en las estadísticas de Homicidio como generalidad, por muchos siglos, encontrando como principal cómplice la indiferencia, vergüenza y tolerancia social.

Si bien el Femicidio no es restrictivo a las clases más pobres de los países latinoamericanos, sí se constata que este fenómeno evidentemente tiene más 
incidencia en entornos socioculturales inferiores que se caracterizan por bajos niveles de educación, y en su mayoría entornos de desempleo o subempleo, no es un incidente aislado de los grupos de la misma que se conseguirá a través de la revisión tanto de la normativa nacional como internacional, la doctrina haciendo énfasis en casos concretos que nos permitan determinar la trascendencia de esta figura en la lucha contra todo tipo de violencia contra la mujer.

No obstante, el concepto "Femicide" concepto que fuere inicialmente desarrollado en los Estados Unidos de América, no puede negarse que ha sido en América Latina donde el concepto se ha estudiado, ampliado y discutido a profundidad, desde múltiples aristas llegando a adquirir una real $\mathrm{e}$ innegable transcendencia internacional, no solo por haberse derivado dos conceptos que si bien es cierto tienen un fin similar, presentan diferencias marcadas de las expresiones "femicidio" y " feminicidio" según algunas teorías, el feminicidio/femicidio como muerte violenta de mujeres, por su condición de mujer, o asesinato de mujeres por razones asociadas al género.

Cuando se utiliza la expresión muerte violenta, se dan un tono enfático a la violencia, ensañamiento, como causante de la muerte de la mujer. Desde la óptica penal se incluyen en esta categoría las muertes que derivan no solo de ser mujer, o de haber mantenido algún tipo de relación sea personal, afectiva, laboral o familiar.

Al tratarse de un delito que por su naturaleza genera gran conmoción social y por tratarse de un tema tan sensible se evidencian múltiples limitaciones al realizar la investigación, la dificultad de obtener información específica por tratarse de una materia reservada. Que como forma de proteger a la víctima, lo que consideran necesario para evitar una mayor estigmatización.

\section{REFERENCIAS BIBLIOGRÁFICAS}

Asamblea Nacional Constuyente, E. (2008). Constitucion de la Republica del

Ecuador. Montecristi: Registro Oficial. 
Asamblea Nacional, E. (2014). Código Orgánico Integral Penal . Quito: Registro Oficial.

Campbell, J. C. (1992). If I Can't Have You, No One Can: Power and Control in Homicide of Female Partners. New York: Twayne Publishers.

Caputi, J. y. (1987). Femicide: Sexist Terrorism against Women. New York: Twayne.

Carcedo, A., \& Sagot., M. (2000). Femicidio en Costa Rica, 1990-1999. San José de Costa Rica: Organización Panamericana de la Salud, Programa Mujer, Salud y Desarrollo.

Copello, P. L. (2012). Apuntes sobre el feminicidio. Revista de Derecho penal y criminología $3^{a}$ época, n. 8, 122.

Godelier, M. (2004). Métamorphoses de la parenté. Paris: Fayard.

Lagarde, M. (2009). Claves feministas en tornos al feminicidio. Madrid: Universidad Autónoma de Madrid.

Lagarde, M. (2014). Conferencia "Retos del Feminismo, hoy". Buenos Aires: Redes de Feministas Argentinas.

Lagarde, M. (2006). Feminicidio: una perspectiva global, México, Comisión Especial para Conocer y Dar Seguimiento a las Investigaciones Relacionadas con los Feminicidios en la República Mexicana y los Feminicidios en la República Mexicana y a la Procuración de Justicia Vinc. Mexico: Diana Russell y Roberta Harmes.

ONU, O. d. (2008). Declaración sobre el Femicidio del Comité de Expertas/os (documento MESECVI/CEVI/DEC. 1/08. New York: Onu.

Radford, J., \& Rusell, D. (1992). Femicide the Polithics of woman killing. New York: Twayn Publishers.

Russell, D. (2006). Feminicidio: una perspectiva global, “Definición de feminicidio y conceptos relacionados; Comisión Especial para Conocer y 
Dar Seguimiento a las Investigaciones Relacionadas con los Feminicidios la República Mexicana y a la Procuración de Justicia Vincul,. México: Diana Russell y Roberta Harmes.

Williams, J. (2009). “Igualdad sin discriminación”, en Ramiro Avila Santamaría, Judith Salgado y Lola Valladares, El género en el derecho. Ensayos críticos,. Quito: Ministerio de Justicia Derechos Humanos y Cultos. 